\title{
DO BACHARELISMO TRADICIONAL AO BACHARELISMO DO SÉCULO XXI: A MASSIFICAÇÃO E A DESELITIZAÇÃO DA GRADUAÇÃO EM DIREITO
}

\author{
FROM THE TRADICIONAL "BACHARELISMO" TO THE TWENTY-FIRST \\ CENTURY "BACHARELISMO": THE MASSIFICATION AND THE LOSS OF \\ THE ELITIST ASPECT OF THE LAW GRADUATION
}

\author{
Felipe José Nunes Rocha \\ Universidade Federal do Maranhão - UFMA - São Luís - Maranhão - Brasil \\ Mônica Teresa Costa Sousa \\ Universidade Federal do Maranhão - UFMA - São Luís - Maranhão - Brasil
}

\begin{abstract}
Resumo: Este artigo tem por objetivo analisar o surgimento e desenvolvimento do fenômeno do bacharelismo no Brasil, partindo de uma análise de elementos culturais, sociais e políticos do período colonial que influenciaram a forma como tal fenômeno surgiu e se consolidou no período imperial. Além disso, pretendese analisar a possibilidade de se falar no surgimento de um novo bacharelismo, no final do século XX e início do século XXI, a partir de dados relativos ao ensino jurídico e aos bacharéis em Direito em tal período, bem como quais seriam os elementos característicos e as consequências desse novo fenômeno. Após a realização da pesquisa, verificou-se que é possível falar em um novo bacharelismo, caracterizado por um processo de deselitização e de massificação das graduações e dos cursos de Direito cujos efeitos são prejudiciais para a cultura jurídica brasileira.
\end{abstract}

Palavras-chave: bacharelismo, Brasil imperial, História do Direito, cursos de direito, século XXI.

Abstract: This article aims to analyze the emergence and development of the phenomenon of "bacharelismo" in Brazil, starting from an analysis of cultural, social and political elements of the colonial period that influenced the way how this phenomenon has emerged and consolidated in the imperial period. Besides, we intend to analyze the possibility of talk about the emergence of a new "bacharelismo", in the end of twentieth century and the beginning of twenty-first century, from legal education and law graduates data in that period and which would be the characteristic elements and the consequences of this new phenomenon. After the research, it was found that it is possible to speak of a new "bacharelismo", characterized by a process of loss of the elitist aspect and massification of law graduations and schools whose effects are harmful to the brazilian legal culture. 
Palavras-chave: "bacharelismo", imperial Brazil, History of Law, law courses, twenty-first century.

\section{Introdução}

A proliferação desenfreada de cursos jurídicos no Brasil, nas últimas décadas, somada ao notório crescimento da atuação dos juristas no cenário político e social hodierno e à complexidade cada vez maior das instituições e normas jurídicas brasileiras têm feito com que a preocupação com a qualidade do ensino jurídico se torne cada vez maior.

Tal preocupação, que é absolutamente legítima, face à relevância das profissões jurídicas para o combate às opressões e às desigualdades sociais, tem gerado questionamentos a respeito da real capacidade das instituições de ensino superior de preparar o jurista para lidar com atribuições tão importantes quanto complexas e sobre os conteúdos, métodos e finalidades dos cursos jurídicos do Brasil.

Neste contexto, afigura-se de suma importância a análise do que muitos historiadores e sociólogos denominaram de "bacharelismo", por se tratar de um fenômeno que marcou profundamente a forma como as instituições do sistema de Justiça e os cursos jurídicos se estruturaram no Brasil, desde a Independência, no início do século XIX.

Por outro lado, a análise de recentes dados estatísticos - qualitativos e quantitativos - a respeito do perfil e do desempenho dos egressos dos cursos de graduação em Direito do Brasil demonstra que, apesar de ainda haver um número muito grande de bacharéis em Direito na sociedade brasileira, o bacharelismo, no cenário contemporâneo, assumiu contornos bastante distintos daqueles característicos do período imperial.

Entretanto, muito pouco se escreveu, até o momento, acerca desse "novo bacharelismo" que tem se desenvolvido desde o final do século XX e no início do século $\mathrm{XXI}$, o que justifica uma análise mais detida sobre o tema em um artigo.

Assim, o objetivo do presente trabalho é verificar se é possível falar no surgimento de um novo bacharelismo no Brasil e, em caso positivo, traçar as 
semelhanças e diferenças entre ele e o bacharelismo tradicional, bem como suscitar reflexões a respeito das consequências dessa nova caracterização do bacharelismo no contexto contemporâneo para a sociedade brasileira.

Para tanto, será feita pesquisa bibliográfica, que partirá dos principais aportes teóricos produzidos no Brasil acerca do tema do bacharelismo e de obras que contêm as estatísticas e os dados necessários para embasar as conclusões do trabalho.

Quanto à estruturação do artigo, em um primeiro tópico, serão feitas considerações a respeito dos fatos históricos que antecederam o surgimento do bacharelismo no Brasil, mas que influenciaram a configuração de tal fenômeno por aqui.

O segundo tópico será destinado a analisar o conceito $e$ as características do bacharelismo no Brasil no período imperial e no início do período republicano.

Já o terceiro item do texto será voltado para a análise dos dados estatísticos qualitativos e quantitativos relativos aos cursos jurídicos e aos bacharéis em Direito do Brasil, ao longo do século XX e início do século XXI, para que se verifique a mudança de cenário que fez com que se formulasse a hipótese de que um novo bacharelismo tem se desenvolvido no Brasil, distinto do tradicional.

\section{Os fatos históricos que antecederam o surgimento do bacharelismo no Brasil}

Como ensina Kozima (2014), a compreensão acerca de como o bacharelismo se desenvolveu no Brasil imprescinde da análise de alguns importantes elementos da experiência colonial pátria, que marcaram profundamente a formação do ethos brasileiro.

Assim, cumpre, em um primeiro momento, analisar os traços do colonialismo brasileiro que contribuíram direta ou indiretamente para 0 surgimento do bacharelismo no período imperial.

Sérgio Buarque de Holanda (1995), em Raízes do Brasil, apresenta alguns elementos importantíssimos da mentalidade e da práxis social e política 
de Portugal, herdados pelo povo brasileiro e que, como se verá adiante, foram marcantes para o surgimento do bacharelismo no Brasil no início do século XIX.

A esse respeito, um primeiro ponto característico dos povos ibéricos que merece destaque é "a invencível repulsa que sempre lhes inspirou toda moral fundada no culto ao trabalho" (HOLANDA, 1995, p. 38), corroborada pela adoção da mão-de-obra escrava, que fez com que se difundisse a ideia de que o trabalho braçal era indigno. Prevalecia, entre eles, a ideia do ócio e das atividades que não são manuais e mecânicas como o ideal a ser perseguido ao longo da vida.

Também decorre dessa aversão ao trabalho, como explica o autor, a dificuldade dos povos ibéricos em promoverem uma organização social pautada na solidariedade, visto que a própria ideia de solidariedade pressupõe uma organização racional e uma coesão que, por sua vez, exigem um arranjo harmônico cujo funcionamento não se adequa bem a uma cultura de repulsa ao trabalho.

Ao invés disso, nos países ibéricos se desenvolveu uma cultura extremamente personalista, que era fundada em uma valorização excessiva do mérito de cada indivíduo e da prevalência de suas relações interpessoais e sentimentais, em detrimento de uma solidariedade social fundada em práticas impessoais e racionais.

Outro elemento característico dos portugueses, que foi herdado pelo povo brasileiro no período colonial e que se relaciona com o personalismo supracitado e com o modo como o bacharelismo se configurou no Brasil, diz respeito à presença marcante do patrimonialismo na forma de lidar com a res pública.

Kozima sintetiza como se deu a formação do Estado patrimonial em Portugal:

Em síntese, Portugal teria vivenciado uma monarquia patrimonial: o rei como senhor de toda a riqueza territorial, do comércio e empreendimentos, cercado por "servidores" que a ele se prendiam por uma relação de acentuada dependência. O estamento formavase, para utilizar a tipologia weberiana, por "recrutamento extrapatrimonial", reconhecidamente aí presentes o "favoritismo" e o "clientelismo", expressões já incorporadas à vida de nossas instituições políticas. Em outras palavras: o rei era o único proprietário 
e o quadro administrativo era formado por pessoas a ele ligadas por relações pessoais de confiança (critérios não racionais). Mais ainda: como desdobramento dessa situação, a apropriação pelo estamento (quadro administrativo) dos "poderes de mando e as correspondentes oportunidades econômicas" sugeriu ao autor qualificar o tipo de forma e concluir por um patrimonialismo estamental. Esse tipo de concepção de Estado é que virá inscrever-se em todas as instituições econômico-políticas portuguesas daquela época. (2014, p. 482)

Holanda (1995), por sua vez, esclarece que a tradição patrimonialista dos agentes públicos brasileiros dificultou a criação de uma burocracia estatal baseada no modelo weberiano impessoal e abstrato, na medida em que compreendia o espaço público como se se tratasse de uma parte do patrimônio dos detentores do poder e que, por isso, era regido pelos mesmos laços pessoais e de afeto que regiam as relações familiares. Assim, a família patriarcal servia de modelo para qualquer composição social, mesmo em instituições públicas que deveriam atender o interesse de toda a sociedade e não só o das pessoas ligadas aos agentes públicos através de vínculos pessoais ${ }^{1}$.

Gilberto Freyre é bastante perspicaz ao explicar que a influência da família patriarcal não se restringia ao âmbito doméstico, quando afirma que:

Vivo e absorvente órgão da formação social brasileira, a família colonial reuniu, sobre a base econômica da riqueza agrícola e do trabalho escravo, uma variedade de funções sociais e econômicas. Inclusive, como já insinuamos, a do mando político: ou oligarquismo ou nepotismo, que aqui madrugou, chocando-se ainda em meados do século XVI com o clericalismo dos padres da Companhia. (1994, p. 22-23)

Ainda quanto aos fatos históricos que antecederam o surgimento do bacharelismo no Brasil, é relevante fazer menção à influência da pedagogia jesuítica sobre o modo como o fenômeno surgiu e se estruturou no país.

Sobre esse assunto, Kozima (2014) afirma que, até a vinda da Família Real portuguesa para o Brasil, em 1808, a educação na colônia se resumia às experiências jesuíticas da Companhia de Jesus, que se caracterizavam por uma tendência literária, que desprezava o trabalho técnico e produtivo.

\footnotetext{
${ }^{1}$ Sérgio Buarque de Holanda, ao falar sobre a família patriarcal, aduz que "este núcleo bem característico em tudo se comporta como seu modelo da Antiguidade, em que a própria palavra 'família', derivada de famulus, se acha estreitamente vinculada à ideia de escravidão, e em que mesmo os filhos são apenas os membros livres do vasto corpo, inteiramente subordinado ao patriarca, os liberi”. (1995, p. 81).
}

Revista do Direito UNISC, ISSN: 1982-9957

Santa Cruz do Sul №. 48 | p. 3-30 | JAN-ABR 2016

https://online.unisc.br/seer/index.php/direito/index 
Além disso, "a pedagogia jesuítica inspirava-se na ratio studiorum (sistematização de regras padronizadas), dando demasiada ênfase à retórica e privilegiando poucos autores, designadamente Aristóteles e Tomás de Aquino" (KOZIMA, 2014, p. 486). Fatos estes que, somados à postura do Estado português de se manter distante dos significativos avanços que ocorreram na Europa desde o Renascimento até o lluminismo, por orientação da doutrina da contrarreforma, dificultaram a assimilação, pela cultura portuguesa, de novas práticas pedagógicas e dos valores liberais que, mais tarde, estariam na base da sociedade capitalista. Além do que, também corroboraram a cultura de aversão ao trabalho manual, na medida em que Aristóteles, Tomás de Aquino e alguns outros pensadores que eram lidos pelos jesuítas consideravam o trabalho braçal indigno (KOZIMA, 2014).

Sabe-se que a vinda da Corte Real portuguesa para o Brasil, em 1808, trouxe grandes inovações culturais para a colônia, visto que ela deveria estar adequadamente estruturada para receber tanto a Família Real quanto toda a classe de nobres que se deslocou com ela da metrópole para este país. Foi naquele contexto, aliás, que surgiram as primeiras instituições de ensino superior brasileiras. Entretanto, como ensina Kozima:

[...] a instalação da Corte não suscitou de imediato a preocupação com a formação de quadros para ocupar os cargos e funções do Estado - leia-se bacharéis. Convinha não descuidar das idéias e, nesta seara, melhor seria manter a dependência da Colônia, pois, conforme anotado pela historiografia brasileira, a formação coimbrã consistiu em eficiente método de controle ideológico. [...]

Assim, a preocupação com o ensino superior resumiu-se à formação militar e às outras áreas consideradas técnicas, a exemplo da engenharia, economia e medicina. Embora se possa dizer que, lato sensu e por extensão, estas últimas áreas tenham produzido bacharéis, no sentido de formação superior, reserva-se o vocábulo para aqueles com formação humanística e, destacadamente, é certo, aos saídos das academias de direito, este o bacharel genuíno, o elemento nuclear do fenômeno conhecido por bacharelismo. (2014, p. 488-489)

Na verdade, apenas após o Brasil se tornar independente, em 1822, sob o comando de Dom Pedro I, é que se fez necessária a criação de cursos de Direito que preparassem os membros da elite que iriam ocupar os espaços de poder do Império. 


\section{O bacharelismo surgido no período imperial}

De fato, somente em 1827, quando o Brasil já era um país independente e já possuía, inclusive, uma Constituição própria, é que foram criados os dois primeiros cursos de Direito do país (um na cidade de São Paulo e outro em Olinda, posteriormente transferido para Recife), com o intuito de atender as demandas políticas e sociais das elites que conduziam o Império. Sérgio Adorno explica que:

A criação e fundação dos cursos jurídicos no Brasil, na primeira metade do século XIX, nutriu-se da mesma mentalidade que norteou a trajetória dos principais movimentos sociais que resultaram na autonomização política dessa sociedade: o individualismo político e o liberalismo econômico. A constituição do Estado Nacional reclamou tanto a autonomização cultural quanto - e sobretudo - a burocratização do aparelho estatal. [...] Com a emergência do Estado Nacional, suscitou-se o delicado problema da autonomização cultural da sociedade brasileira, além da necessidade de formar quadros para o aparelho estatal. Nesse contexto, aos homens que haviam promovido e dirigido o curso da revolução descolonizadora não thes parecia recomendável que essa sociedade se mantivesse dependente das universidades europeias, sobretudo a de Coimbra. $(1988$, p. 77 e 81$)$

Este foi o cenário em que, no Brasil, deu-se o surgimento do que Sérgio Buarque de Holanda denominou de a "praga do bacharelismo" (1995, p. 156).

Em "Raízes do Brasil", Holanda (1995) esclarece que o bacharelismo é um fenômeno que não é exclusivamente brasileiro, posto que também ocorreu em países como os Estados Unidos, e que decorre de uma supervalorização do diploma de bacharel em Direito, por ser tal título visto como a via de acesso às profissões liberais mais bem remuneradas e que alcançavam os mais importantes espaços de poder ${ }^{2}$. Isto porque, como afirma Venâncio Filho:

Os cursos jurídicos foram, assim, no Império, o celeiro dos elementos encaminhados às carreiras jurídicas, à magistratura, à advocacia, e ao Ministério Público, à política, à diplomacia, espraiando-se também em áreas afins na época, como a filosofia, a literatura, a poesia e a ficção, as artes e ao pensamento social. Constituíram, sobretudo, a pepineira da elite política que nos conduziu durante o Império. Numa frase muitas vezes citada, e algumas vezes deturpada, disse Joaquim

\footnotetext{
${ }^{2}$ Neste ponto, é interessante transcrever a observação de Wolkmer, no sentido de que "na prática, o sucesso do bacharelismo legalista devia-se não tanto ao fato de ser uma profissão, porém, muito mais uma carreira política, com amplas alternativas no exercício público liberal, pré-condição para a montagem coesa e disciplinada de uma burocracia de funcionários" (2010, p. 127)
} 
Nabuco que "já então (década de 1840 e 1850) as faculdades de Direito eram ante-salas da Câmara" (2004, p. 273).

Holanda (1995) também pondera que a difusão de tal fenômeno no Brasil se relaciona diretamente com a cultura personalista que bem acolhia a ideia de que era possível o bacharel ter atendida a sua ânsia por segurança e estabilidade com um mínimo de esforço, através de uma conduta profissional cômoda, que pouco se preocupava com assuntos que demandavam muitos esforços da inteligência.

Feita essa breve contextualização histórica, que é suficiente para explicar o motivo pelo qual Kozima conceitua o bacharelismo como sendo "a situação caracterizada pela predominância de bacharéis na vida política e social do país" (KOZIMA, 2014, p. 492), passa-se a discorrer sobre algumas importantes características do ensino jurídico no período imperial que são cruciais para que se compreenda a configuração do bacharelismo naquele momento histórico.

Apesar da importância do bacharel em Direito no cenário político do período imperial, poder sugerir que o Império teria concedido às primeiras faculdades de Direito estrutura adequada ao seu funcionamento em face do relevante papel que desempenhavam, a verdade é que, tanto no tocante à estrutura física quanto ao corpo docente, as faculdades de São Paulo e de Olinda deixaram muito a desejar desde a sua instalação.

Nesse sentido, Venâncio Filho observa que:

As dificuldades para o funcionamento dos cursos eram, porém, de toda ordem, tanto quanto às instalações materiais como quanto ao pessoal. Em relação às instalações materiais tiveram os cursos jurídicos de se abrigar à sombra de velhas instituições eclesiásticas, 0 que ocorreu tanto em São Paulo quanto em Olinda. (2004, p. 37)

Já no tocante à composição do quadro docente e à consequente má qualidade do ensino, é interessante transcrever a observação de Adorno sobre os fatores que fizeram com que a formação do bacharel se desse muito mais fora da sala de aula. Vejamos:

[...] As permanentes críticas dirigidas contra a má qualidade de ensino e contra própria habilitação do corpo docente, formuladas até mesmo por acadêmicos que vivenciaram esse processo educativo àquela época, sugerem que a profissionalização do bacharel se operou fora do contexto das relações didáticas estabelecidas entre 0 
corpo docente e o corpo discente a despeito das doutrinas jurídicas difundidas em sala de aula. (ADORNO, 1998, p. 93)

Por outro lado, embora fosse de se esperar que tais problemas estruturais fossem saneados com o passar do tempo, o fato é que, mesmo após o encerramento do Primeiro Reinado e do Período Regencial e o advento do Segundo Reinado, a situação não divergia muito. Como afirma Venâncio Filho:

\begin{abstract}
Ao findar o Império o ensino jurídico continuava restrito às duas faculdades de São Paulo e do Recife. [...] Se, quantitativamente, o ensino jurídico permanecia na mesma posição de 1827, pode-se afirmar, com a consulta às fontes idôneas dos biógrafos e dos memorialistas, às Memórias Históricas e aos relatórios dos diretores de faculdades, aos depoimentos dos contemporâneos e às reminiscências dos estudantes, que qualitativamente a situação também não se modificara. (2004, p. 113)
\end{abstract}

$\mathrm{Na}$ verdade, ante os baixos salários destinados aos docentes, o que ocorria com frequência era que "o ofício de professor era uma atividade auxiliar no quadro do trabalho profissional. A política, a magistratura, a advocacia, representavam, para os professores, na maioria dos casos, a função principal" (VENÂNCIO FILHO, 2004, p. 119), o que por certo contribuía para a má qualidade do ensino jurídico da época.

Diante dessa conjuntura, o que ocorreu foi que os cursos de Direito, ao invés propiciar a efetiva formação de uma elite intelectual que fosse razoavelmente coesa preparada, destinou-se mais a distribuir o status necessário para a ocupação dos cargos públicos que integravam o quadro burocrático em expansão (KOZIMA, 2014).

De fato, embora os bacharéis do período imperial sejam considerados grandes difusores das ideias liberais importadas da Europa, a verdade é que:

[...] seria mais plausível atribuir o "mérito" pela consolidação das ideias liberais como ideologia hegemônica entre as elites dirigentes ao próprio fenômeno natural, consistente na propagação dessas ideias pelo mundo afora pelos mais diversos veículos - o que decorreu do próprio desdobramento do capitalismo industrial -, que ao ensino oferecido pelas faculdades de direito; estas apenas teriam facilitado a difusão das idéias e a troca de informações e referências bibliográficas. (KOZIMA, 2014, p. 490)

Assim, não era de causar espanto o fato de que:

[...] muitos dos bacharéis que se sobressaíram como juristas, políticos ou advogados tenham tido uma formação de linha autodidática,

Revista do Direito UNISC, ISSN: 1982-9957

Santa Cruz do Sul №. 48 | p. 3-30 | JAN-ABR 2016

https://online.unisc.br/seer/index.php/direito/index 
possuindo poucas recordações intelectuais dignas de memória que se reportem à experiência acadêmica, notadamente quanto aos professores, tendo, outrossim, pouco se distinguido como estudantes de direito. (KOZIMA, 2014, p. 491)

Além disso, muito contribuiu para a formação profissional desses bacharéis as atividades que eram desenvolvidas na faculdade, mas fora da sala de aula, a exemplo da participação em grêmios estudantis, em jornais acadêmicos - em que, além do conteúdo informativo, havia espaço tanto para textos literários quanto para poesia -, em teatros, dentre outros.

Com efeito, Venâncio Filho sintetiza bem tal fato, ao afirmar que, naquela época, "ser estudante de Direito era, pois, sobretudo, dedicar-se ao jornalismo, fazer literatura, especialmente a poesia, [...] ser bom orador, participar dos grêmios literários e políticos, das sociedades secretas e das lojas maçônicas" (2004, p. 136).

Todavia, também é importante observar que, em estudo mais recente acerca do surgimento dos cursos jurídicos brasileiros e da formação dos primeiros bacharéis, Ricardo Marcelo Fonseca contesta a conclusão de Sérgio Adorno no sentido da "inutilidade" do ambiente acadêmico para a formação do bacharel, por considerar que tal autor ignora os traços marcantes da cultura jurídica da época. Diz Fonseca:

O ponto que parece faltar a Adorno, então, é precisamente um aporte genuinamente historiográfico jurídico, ou seja, uma avaliação da qualidade eminentemente jurídica (bem como o seu impacto sobre o campo jurídico da época) da produção das academias que fosse levada a efeito. O porte teórico dos trabalhos dos juristas, incluindo a avaliação do tipo de herança recebida pela cultura jurídica européia e a qualidade da sua "adaptação" pelos mestres brasileiros não é uma estratégia utilizada por Adorno antes que ele decretasse a inutilidade, em termos de produção teórica, das faculdades de direito do império. [...] Assim, dentro desse contexto, perde sentido a tentativa de Adorno em opor ou confrontar a 'academia formal' com a "academia real". Essa dualidade remete a uma dualidade entre um saber jurídico "puro" (que seria, ao que parece, um saber dos códigos e das leis) e um outro saber "não jurídico" (que seria composto de toda uma carga dos saberes da retórica, das letras, etc.). Tal dualidade, porém, na realidade não existia, já que ambas formavam uma unidade que não pode ser compreendida, dentro dos moldes da cultura jurídica brasileira do século XIX, de um modo separado. (2008, p. 292)

Vale destacar que Fonseca (2008) também reconhece que, embora a formação universitária da época refletisse a cultura jurídica do período imperial, muito marcada pela oratória e pela valorização do que ele chama de "juristas

Revista do Direito UNISC, ISSN: 1982-9957

Santa Cruz do Sul №. 48 | p. 3-30 | JAN-ABR 2016

https://online.unisc.br/seer/index.php/direito/index 
eloquentes", é somente a partir da década de 1860 que começam a ser lançadas, no Brasil, as bases para formação dos "juristas cientistas", cuja práxis jurídica é pautada em uma argumentação revestida de rigor científico. Fato este que, inclusive, ajuda a explicar o motivo pelo qual havia uma preocupação maior em "parecer" erudito do que efetivamente em sê-lo.

Pois bem, após essa caracterização do ensino jurídico no Período Imperial, resta analisar os elementos referentes ao perfil dos bacharéis em Direito daquele momento histórico, que também são importantes para que se possa compreender as características do bacharelismo brasileiro surgido no século XIX.

Em síntese, pode-se afirmar que o bacharel em Direito do período imperial, em verdade, pouco correspondia à imagem que a sua aparência transmitia: a de uma pessoa erudita - versada não só nas ciências jurídicas, mas também em outros ramos do saber e nas artes -, imbuída de ideias e ideais liberais bastante progressistas para a época e que muito poderia contribuir para o desenvolvimento e modernização do país.

Quanto à distância entre o discurso liberal e a atuação política dos bacharéis, Kozima aduz o seguinte:

\begin{abstract}
Nada obstante a ascensão do bacharel tipicamente brasileiro, que trouxe consigo os ideais do lluminismo, o que se verifica é que não houve, nem poderia haver, a conformação do Estado, efetivamente, às idéias liberais, o que, em outras palavras, poderia significar a substituição do modelo tradicional por uma forma de dominação de tipo racional, nos moldes weberianos. Também a qualidade das relações sociais não sofreu qualquer alteração significativa, antes 0 que houve foi a incorporação daqueles elementos à estrutura estabelecida, já delineada, ainda que em primeiros traços, desde a experiência das capitanias hereditárias, dando ensejo a uma interessante contradição entre o discurso e a prática, o que, aliás, se verifica até os dias de hoje. Vá lá que se tenha, não sem hesitações, abolido definitivamente a escravidão, prática absolutamente incompatível com o modelo econômico liberal, e, mesmo dentro de uma confusão de fatos, tenha sido instaurado o regime republicano; mas daí a incorporar, sem maiores senões, valores que não estavam presentes na prática cotidiana das relações sociais vai grande distância. (2014, p. 493-494)
\end{abstract}

Por outro lado, quanto ao apego exagerado à aparência de erudição, era possível percebê-la na utilização de uma retórica que, mais do que servir para tornar o argumento convincente, visava simplesmente, através de um palavreado rebuscado e hermético, ornamentar o discurso, cuja persuasão 
advinha não da racionalidade e consistência da argumentação, mas sim da autoridade que tal aparência conferia ao sujeito que proferia esse "discurso competente"3.

Ainda a esse respeito, convém transcrever a descrição feita por Wolkmer dessa cultura dos bacharéis:

Ninguém melhor do que eles para usar abusar do uso incontinente do
palavreado pomposo, sofisticado e ritualístico. Não se pode deixar de
chamar a atenção para o divórcio entre os reclamos mais imediatos
das camadas populares do campo e das cidades e o proselitismo
acrítico dos profissionais da lei que, valendo-se de um intelectualismo
alienígeno, inspirado em princípios advindos da cultura inglesa,
francesa ou alemã, ocultavam, sob o manto da neutralidade e da
moderação política, a institucionalidade de um espaço marcado por
privilégios econômicos e profundas desigualdades sociais. Na
verdade, o perfil do bacharel juridicista se constrói numa tradição
pontilhada pela adesão ao conhecimento ornamental e ao cultivo da
erudição linguística. Essa postura, treinada no mais acabado
formalismo retórico, soube reproduzir a primazia da segurança, da
ordem e das liberdades individuais sobre qualquer outro princípio.
(2010, p. 85-86)

Kozima, por outro lado, ressalta que esse uso ornamental da retórica "impregnou-se no discurso do bacharel, atando-o à forma desprovida de conteúdo, o que às vezes decorre da própria insustentabilidade do discurso, da ausência de conteúdo defensável” (2014, p. 498). E também salienta que:

[...] em muitas ocasiões o discurso jurídico presta-se a esconder o objeto, ao invés de revelá-lo, como se pretenderia numa ação comunicativa, o que, não raro, pode decorrer do próprio despreparo técnico-jurídico, a que socorre, bem a propósito, a "cultura literária", com citações de fragmentos, supostamente definitivos, fora de contexto, a "frase lapidar" a que se refere Buarque de Holanda, os brocardos latinos digeridos de afogadilho, etc. (KOZIMA, 2014, p. 498)

Vê-se, portanto, que além de buscar ocupar os espaços de poder a que tinham acesso com o diploma de graduação em Direito, os bacharéis do século XIX também buscavam o "poder simbólico"4 que as suas vestimentas,

\footnotetext{
${ }^{3}$ Marilena Chauí conceitua o que chama de "discurso competente" como sendo "aquele no qual a linguagem sofre uma restrição que poderia ser assim resumida: não é qualquer um que pode dizer a qualquer outro qualquer coisa em qualquer lugar e em qualquer circunstância. $O$ discurso competente confunde-se, pois, com a linguagem institucionalmente permitida ou autorizada, isto é, com um discurso no qual os interlocutores já foram previamente reconhecidos como tendo o direito de falar e ouvir e, enfim, no qual o conteúdo e a forma já foram autorizados segundo os cânones da esfera de sua competência" (CHAUÍ, 2006, p. 08).

${ }^{4}$ O poder simbólico, nos dizeres de Pierre Bourdieu, é "esse poder invisível o qual só pode ser exercido com a cumplicidade daqueles que não querem saber que Ihe estão sujeitos ou mesmo que o exercem" (Bourdieu, 2004, p. 7-8)
}

Revista do Direito UNISC, ISSN: 1982-9957

Santa Cruz do Sul №. 48 | p. 3-30 | JAN-ABR 2016

https://online.unisc.br/seer/index.php/direito/index 
discursos e escritas lhe conferiam em um cenário social pobre e inculto em que a população não tinha condições de questionar a credibilidade e a autenticidade do que eles defendiam de forma tão eloquente.

Para concluir o presente tópico, resta apenas tecer algumas considerações sobre a crise do bacharelismo tradicional, ocorrida no período republicano $^{5}$, para que se possa compreender o contexto histórico que precedeu o advento de uma nova "praga do bacharelismo" (HOLANDA, 1995) no final do século XX e início do século XXI.

Um dos fatores que contribuíram para a crise do bacharelismo ocorrida no período da República Velha foi o fato de os militares terem passado a participar cada vez mais do cenário político nacional, com a proclamação da República, ocasionando um crescente desinteresse pela obtenção do diploma de bacharel em Direito.

Sobre o assunto, é pertinente transcrever as lições de Alberto Venâncio Filho:

Proclamada a República, acentua-se o predomínio da classe militar. Phaelante da Câmara, na Memória Histórica de 1903, declara que: Com a Proclamação da República, o prestígio da farda seduziu por tal forma a juventude das escolas que as academias civis se despovoaram.

Preferia-se à toga pretexta de Tibério Gracco as insígnias dos legionários de César, vencedor.

A mocidade ardorosa e otimista sonhava com os alamares da farda sugestiva de Deodoro, e, matriculando-se nas escolas de guerra, os rapazes acreditavam levar na patrona, como soldados de Napoleão, as divisas do marechalato. [...]

Essa situação levou ao desinteresse pela profissão jurídica e pelo decréscimo de matrículas nas faculdades de Direito. [...] Gilberto Freire apontou no seu livro Ordem e Progresso, duas novas influências que se exercem a partir do fim do século passado diminuindo a exclusividade do ensino jurídico em relação a tipos de formação cultural entre os quais se passam a sobressair a influência militar e a influência tecnológica.

No período, houve o messianismo tanto pré-republicano como pósrepublicano em torno da Engenharia, outra em torno da Medicina. (2004, p. 285 e 286)

Naquele contexto, em que as divergências entre militares e bacharéis também se acirraram no campo político, onde civis e militares disputavam o protagonismo na condução da República recém-inaugurada, é que termos

\footnotetext{
${ }^{5}$ A referida análise será bastante breve e superficial em razão das limitações estruturais do presente artigo e por ser algo cujo aprofundamento não é necessário para a compreensão do tema deste trabalho.
} 
como "bacharelismo" e "bacharelice" passam a ser utilizados de forma depreciativa, de modo a denunciar a má formação, a incapacidade técnica e a superficialidade do discurso dos bacharéis, bem como os efeitos nocivos da presença maciça dos bacharéis no Estado brasileiro (VENÂNCIO FILHO, 2004).

Neste ponto, é interessante transcrever um fragmento da obra "Funcionários e Doutores" de Tobias Barreto, escrita em 1917, que ilustra as críticas acima mencionadas. Diz o referido autor:

Esta excessiva produção de homens formados não poderia deixar de acarretar gravíssimos resultados. Se o fundo de cultura desses doutores nem sempre é de grande solidez, as suas aspirações, dificultadas pelo aumento de concorrência, não deixam de ser elevadas. A "Carta" dá-lhes a impressão de pertencer a uma casta superior, destinada a guiar o país; por outro lado, a profissão, explorada por tão grande exército, não abre campo de situações prósperas. As aspirações não acham terreno para as realizações, e o Estado passa a ser a Providência de todos esses necessitados. Se o Estado não tem recurso para bastar a todos, os descontentes reforçam a multidão que não compreende viver no Brasil sem a segurança do ordenado pago pelo Tesouro. Deste modo, à corte dos funcionários junta-se a falange dos doutores que lhes traz os elementos mais vivos e exigentes.

Prestar-se-ia ao Brasil o maior dos serviços, convencendo a mocidade de que ela se deve voltar para as profissões normais, encaminhando-se para as faculdades apenas as aptidões inconfundíveis. Nós vemos serem destinados a elas indistintamente os aptos e os ineptos pela simples razão de que é bom tom ser estudante em vez de caixeiro, e doutor em vez de negociante. (TOBIAS BARRETO apud VENÂNCIO FILHO, 2004, p. 287-288)

Independentemente do quão (in)justas tenham sido as críticas ao bacharelismo surgidas no período republicano, o fato é que, com o passar do tempo, o prestígio que os bacharéis em Direito possuíam no cenário político imperial entrou em crise, tendo em vista que, como explica Alberto Venâncio Filho (2004), o interesse governamental passou a ser o de criar cursos técnicos de nível superior, em atendimento às exigências de formação de pessoal em uma sociedade em processo de industrialização.

Além disso, a formação inadequada que era proporcionada pelas faculdades de Direito fez com que os bacharéis não fossem capazes de atender às exigências decorrentes de um processo crescente de intervenção do Estado na economia. 
Isto porque, tal processo carecia da produção de normas jurídicas em setores cada vez mais amplos, as quais demandavam um conhecimento econômico mais especializado que, por não poder ser obtido junto aos juristas, passou a ser procurado em outros profissionais, como engenheiros, economistas, administradores ou tecnocratas (VENÂNCIO FILHO, 2004).

Na conclusão de sua obra, escrita em 1977, Venâncio Filho, aduz que:

\begin{abstract}
No ano do sesquicentenário da fundação dos cursos jurídicos no Brasil, o ensino do Direito ainda se encontra à procura de seus caminhos. Rebaixado da posição de primazia que ocupou durante o Império, e mesmo no início da República, debate-se perplexo, entre uma inspiração frustrada impossível de pretender ministrar um tipo de cultura geral, para o qual não está preparado, ou converter-se de fato numa escola profissional de bom padrão, fornecendo um pessoal qualificado, que os reclamos de desenvolvimento da sociedade brasileira está a exigir. Esta é a tarefa magna que o país espera do ensino jurídico, e o conhecimento do que foi o seu passado deve constituir guia e inspiração para o seu futuro (2004, p. 335)
\end{abstract}

Assim, conclui-se que a crise do bacharelismo surgido no período imperial, que foi analisada no presente tópico, permanece até os tempos atuais, inobstante as várias reformas educacionais pelas quais o país passou ao longo dos anos.

\title{
4. O bacharelismo do século XXI
}

O fato de o diploma de bacharel em Direito, no período republicano, ter perdido grande parte da importância que tinha no período imperial fez com que o crescimento do número de matrículas nos cursos de graduação em Direito ao longo da primeira metade e das primeiras décadas da segunda metade do século $X X$ tenha se dado de maneira módica, se comparado ao aumento do número de instituições de ensino superior no país e das matrículas por elas ofertadas.

De fato, como se pode observar no Gráfico 1 de um estudo realizado por Edson Nunes e Márcia Carvalho, denominado "O Ensino e a Profissão Jurídica no Brasil: uma visão quantitativa" (2005), o crescimento do número de matrículas nos cursos de Direito no período de 1907 a 1968 é relativamente pequeno, considerando que ao longo desses sessenta anos, a quantidade total 
de matrículas no Ensino Superior subiu de 5.948 para $278.295^{6}$. Para tornar mais claro o que está sendo dito, cumpre transcrever o gráfico acima mencionado:

Gráfico 1 - Evolução das Matrículas do Curso de Direito - Brasil - 1907-2003

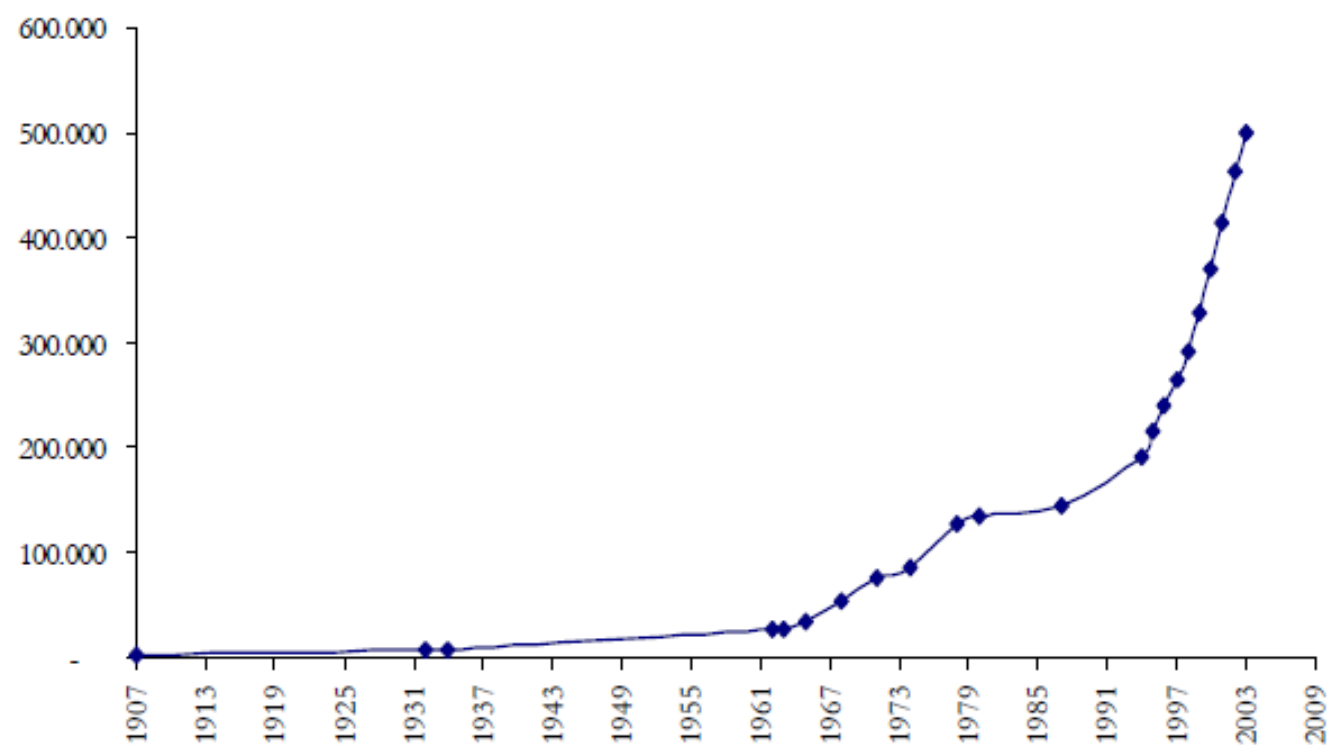

(Fonte: NUNES; CARVALHO, 2005, p. 45)

Do mesmo modo, a partir de uma análise do Gráfico 4 do estudo acima mencionado, também se observa que, como era de se esperar, o número de bacharéis no período acima mencionado também cresceu em proporção relativamente pequena. Eis o gráfico em questão:

\footnotetext{
${ }^{66}$ Tais números podem ser colhidos na Tabela 41 do mesmo estudo (NUNES; CARVALHO, 2005) 
Gráfico 4 - Evolução dos Concluintes de Direito - Brasil - 1933-2003

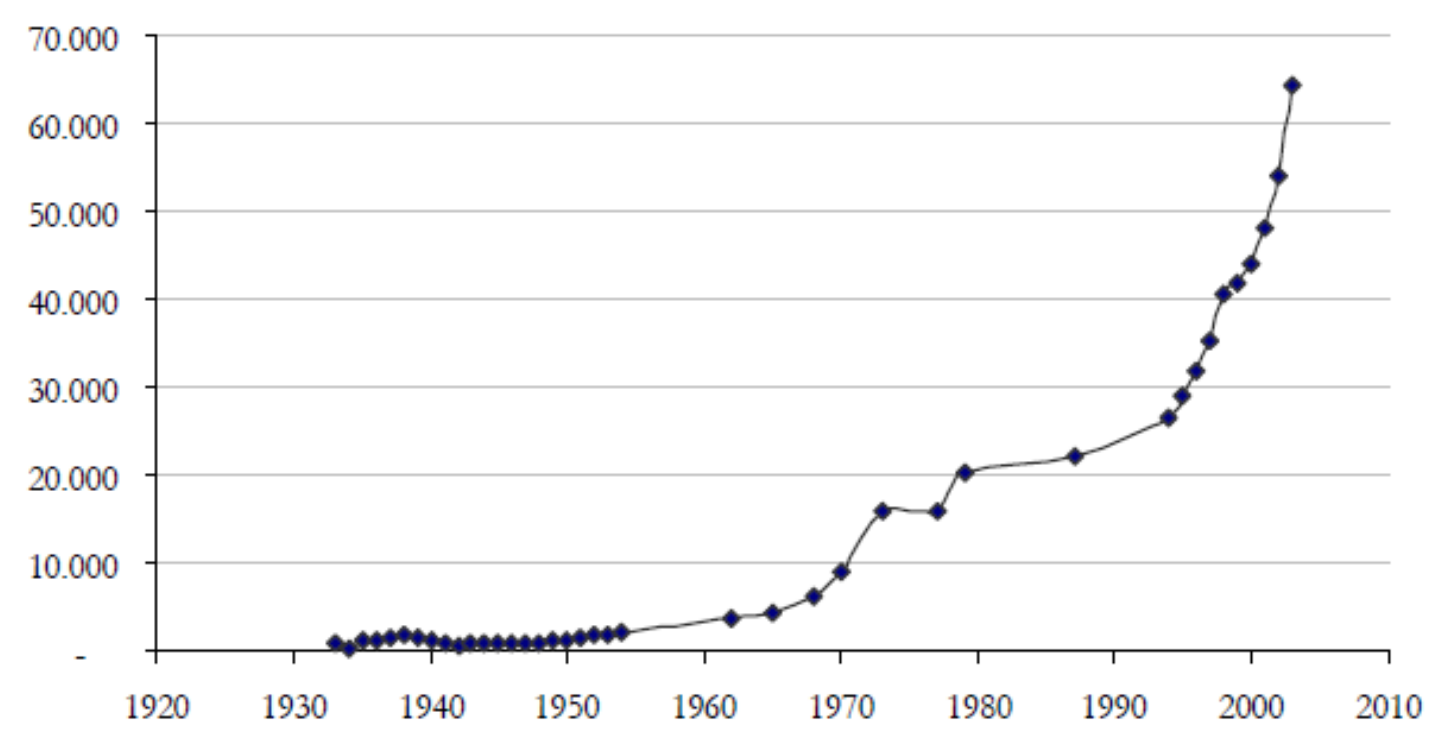

(Fonte: NUNES; CARVALHO, 2005, p. 48)

Por outro lado, um fato que não passa despercebido de ambos os gráficos transcritos é que, se nas primeiras décadas do século $X X, 0$ crescimento do número de matrículas e de graduações em Direito foi relativamente pequeno, no final do século passado e no início do século XXI o número de matrículas e o de graduações cresceram de forma exponencial.

À primeira vista, seria de se estranhar esse crescimento exacerbado, já que não houve qualquer mudança no cenário político e jurídico dos últimos anos que tenha feito a demanda por serviços dos bacharéis em Direito crescer de maneira proporcional ao crescimento da oferta.

Todavia, analisando-se mais dados estatísticos relativos ao ensino jurídico no Brasil, não é difícil entender a razão desse crescimento vertiginoso: ele se deve ao enorme crescimento da quantidade de cursos de Direito no Brasil e, consequentemente, do número de vagas oferecidas principalmente por instituições de ensino superior privadas.

Com efeito, um estudo realizado pela Fundação Getúlio Vargas (2014) intitulado "Exame de Ordem em Números" mostra que, no período de 1995 a 2012, a quantidade de cursos de Direito deste país saltou de 232 para 1.158, o que fez com que a quantidade de cursos de Direito do Brasil passasse a ser 
superior à soma de todos os cursos de todos os países do mundo juntos (ORDEM DOS ADVOGADOS DO BRASIL, 2014).

No que diz respeito à quantidade de matrículas em faculdades de Direito, segundo o mesmo estudo realizado pela FGV (2014), enquanto em 1995 o número era de 215 mil, em 2012 essa quantidade saltou para a extraordinária cifra de 732 mil.

Já, o número de concluintes, que, segundo Nunes e Carvalho (2005), era de 29.122 em 1995, passou a ser de 97.926 em 2012, conforme os dados da FGV (2014).

Diz-se, por outro lado, que as instituições de ensino superior privadas são as principais responsáveis por esse crescimento exacerbado pelo fato de que, enquanto, em 1994, o número de matrículas e de cursos de Direito nas instituições públicas de ensino superior correspondiam a, respectivamente, $22 \%$ e $32 \%$ do total e o de concluintes a $25 \%$ do total (NUNES; CARVALHO, 2012), em 2012, as instituições públicas foram responsáveis por oferecer apenas $11,6 \%$ das faculdades de Direito e 12,2\% das matrículas ofertadas e por graduar apenas $13,2 \%$ do total de bacharéis em Direito que se formaram naquele ano (FUNDAÇÃO GETÚLIO VARGAS, 2014).

Assim, em um cenário em que as instituições privadas são responsáveis pela formação de quase $90 \%$ dos estudantes que se tornam bacharéis em Direito no país $(86,8 \%)$, não há qualquer dúvida de que o aumento do número de cursos e de profissionais da área está diretamente atrelado à oferta fornecida pelas instituições particulares.

Neste ponto, também é útil apresentar as ressalvas contidas na pesquisa feita pela Fundação Getúlio Vargas, no sentido de que esse exorbitante crescimento do número de estudantes de Direito e juristas não se deve apenas ao aumento da oferta de cursos jurídicos - que foi favorecida pela remoção de obstáculos institucionais e legais ao funcionamento das instituições privadas de educação superior, operada pela Lei no 9.394/96 ${ }^{7}$-, mas também a outros fatores relacionados a mudanças no perfil da sociedade brasileira e a incentivos governamentais. Ei-las:

\footnotetext{
${ }^{7}$ Lei de Diretrizes e Bases da Educação Nacional 


\begin{abstract}
Além da expansão da oferta, houve também alterações significativas no perfil socioeconômico do estudante universitário brasileiro, sobretudo nos estratos sociais mais pobres. Segundo dados da Pesquisa Nacional por Amostra de Domicílios (Pnad), a proporção dos estudantes do ensino superior que estavam na primeira metade da distribuição de renda (isto é, os $50 \%$ mais pobres) passou de $6 \%$ para $19 \%$ entre 2001 e 2011.

Esses avanços no campo educacional se traduzem na melhoria geral das condições de vida da população brasileira. Conforme o Atlas do Desenvolvimento Humano (2013),13 entre 1991 e 2010, o Índice de Desenvolvimento Humano Municipal (IDH-M) do Brasil elevou-se em $47,5 \%$, passando de 0,493 para 0,727. Parte significativa desse desempenho se deveu à contribuição do componente "Educação" do IDH-M14 e ao aumento do fluxo escolar de crianças e jovens, cujo subíndice apresentou uma evolução de $128,3 \%$ no período avaliado. Outro fator crucial para explicar o maior acesso à educação superior envolveu $o$ conjunto de políticas públicas e programas governamentais direcionados à sua universalização, com destaque para a oferta de crédito estudantil (subsidiado) e a concessão de bolsas de estudos. Destacam-se nesse âmbito: o Fundo de Financiamento ao Estudante do Ensino Superior (Fies), o Programa Universidade para Todos (ProUni), o Programa de Apoio aos Planos de Reestruturação e Expansão das Universidades Federais (Reuni) e a Universidade Aberta do Brasil (UAB). Considerando-se apenas o Fies e o ProUni, o número de beneficiários em cursos de graduação era de aproximadamente 1,7 milhão de estudantes em 2013. (FUNDAÇÂO GETÚLIO VARGAS, 2014, p. 23-24)
\end{abstract}

Feita essa contextualização da conjuntura hodierna nacional, que mostra que no final do século $X X$ e início do século $X X I$ houve um crescimento vertiginoso do número de bacharéis em Direito, considera-se possível falar no surgimento de um novo bacharelismo no Brasil.

É bem verdade que, como visto no tópico anterior, o bacharelismo vem sendo utilizado pelos estudiosos com diversos significados. Tal categoria ora é vista como a predominância dos bacharéis em Direito no cenário político e cultural do país (KOZIMA, 2014) ou como "a composição social e ideológica das elites políticas a partir da formação superior jurídica" (ALMEIDA, 2010), ora é conceituada a partir de elementos relativos ao comportamento dos bacharéis, o que se pode depreender do fato de Afonso Arinos definir o bacharelismo como sendo "a técnica jurídica aplicada especialmente à atividade política" e dizer que tal fenômeno "não é teórico, sobretudo não é abstrato nem filosófico" (apud VENÂNCIO FILHO, 2004, p. 291-292).

Além disso, como ensina Venâncio Filho (2004), até mesmo Rui Barbosa renegava veementemente o conceito de bacharelismo, por considerá- 
lo pejorativo. Fato este que evidencia que, além de um sentido quantitativo, a referida expressão também já foi utilizada com um viés qualitativo.

Entretanto, independentemente dos significados até então atribuídos a tal expressão, considera-se possível reconhecer o surgimento de um novo bacharelismo no Brasil, nesse contexto do final do século XX e início do século $X X I$, que é bastante diferente daquele surgido no século XIX, mas que também pode ser conceituado como bacharelismo.

Isto porque foi justamente a excessiva proliferação de bacharéis no contexto do Brasil Imperial - semelhante à que se tem atualmente, embora em menor proporção -, que fez surgir a discussão acerca do fenômeno sob análise e que fez com que o historiador Sérgio Buarque de Holanda falasse no surgimento da "praga do bacharelismo" (1995, p. 156) no período imperial.

Resta, então, apresentar os elementos característicos desse fenômeno que, doravante, será denominado de "novo bacharelismo" ou de "bacharelismo do século XXI". . Para tanto, é importante analisar alguns aspectos qualitativos do ensino jurídico pátrio e alguns elementos relacionados ao perfil dos estudantes de Direito e dos bacharéis na conjuntura contemporânea.

Ultimamente, têm sido feitas muitas críticas à qualidade do ensino jurídico no Brasil, seja no tocante aos métodos de ensino utilizados, aos conteúdos exigidos ou à sua capacidade de efetivamente preparar os bacharéis para o exercício das profissões jurídicas que almejam.

Ante as limitações do presente trabalho e as dificuldades de se tratar os dois primeiros aspectos com objetividade científica, o foco da análise qualitativa aqui apresentada será sobre o terceiro aspecto supracitado, sendo os demais abordados de maneira transversal.

\footnotetext{
${ }^{8}$ Apesar de considerar que esse novo bacharelismo surgiu no final do século $\mathrm{XX}$, optou-se pela terminologia "bacharelismo do século XXI" por ter sido nas primeiras décadas deste século que esse fenômeno se consolidou. Afirmação essa que se justifica pelo fato de o número de cursos de Direito no Brasil em 2012 (1.158) ter praticamente triplicado, em relação à quantidade que se tinha no último ano do século XX (442) e do número de matrículas (737 mil) e de graduações $(97.900)$ ter praticamente duplicado em relação às quantidades registradas no ano 2000 (370 mil e 41.900, respectivamente), o que se verifica nos dados colhidos por Nunes e Carvalho (2005) e pela FGV. Também é útil ressaltar que, enquanto a relação de concluintes dos cursos de Direito por habitantes da população brasileira era de um bacharel para cada 5.793 habitantes em 1994 (NUNES; CARVALHO, 2005), em 2012, tal proporção passou a ser de um graduado para cada 1.980 habitantes, de acordo com os dados da FGV (2014) e do IBGE (2015).
} 
Embora não existam critérios seguros de se mensurar o preparo dos bacharéis em Direito para o exercício das profissões da área, há alguns elementos indicativos bastante convincentes que podem ser analisados.

O primeiro deles corresponde ao percentual de aprovados nos Exames de Ordem, realizados pela Ordem dos Advogados do Brasil, com o objetivo de "aferir se o examinando apresenta os conhecimentos teóricos e práticos indispensáveis ao exercício da profissão no país" (FUNDAÇÃO GETÚLIO VARGAS, 2014, p. 17).

Considera-se tal critério adequado para que se tenha pelo menos uma ideia da capacidade das instituições de ensino superior de formar bacharéis aptos para o exercício das profissões jurídicas por se tratar de um exame que abrange as principais matérias que são cobradas nos seletivos das mais diversas profissões jurídicas, além da advocacia, e por ser uma prova em que a aprovação depende apenas da obtenção de uma pontuação mínima pelo indivíduo, não havendo concorrência entre os candidatos e nem limitação prévia do número de aprovados, como determina o Provimento no 144/2011 do Conselho Federal da OAB (OAB, 2015a).

Pois bem, analisando-se as estatísticas de aprovação do II ao XIII Exame de Ordem, realizados no período de 2010 a 2014, quando a FGV Projetos passou a assumir a sua organização, verifica-se que a média nacional de aprovação em todo esse período corresponde a 17,5\% dos inscritos, sendo o menor índice no IX Exame, quando apenas 11,4\% dos inscritos foram aprovados, e o maior índice no VI Exame, quando 26,1\% dos candidatos obtiveram aprovação (FUNDAÇÃO GETÚLIO VARGAS, 2014).

Embora não se tenha dados relativos ao índice de inserção dos bacharéis em Direito nas várias outras carreiras jurídicas que o diploma lhes permite seguir, é razoável supor que tal inserção se dá em um percentual bastante inferior ao da aprovação nos Exames de Ordem, haja vista que o acesso a tais carreiras - como as da magistratura, Ministério Público, de delegados de polícia ou serventuários de justiça - se dá mediante aprovação em concurso público, em que apenas um pequeno grupo formado pelos candidatos com melhores desempenhos é que chega a ocupar tais cargos públicos. 
Assim, o que se pode concluir é que os cursos de Direito, em sua maioria, não conferem qualificação adequada aos bacharéis para que eles consigam exercer as profissões da área, seja na advocacia particular ou na carreira pública.

Outros dados que reforçam tal conclusão são aqueles relacionados ao quantitativo de bacharéis em Direito que efetivamente atuam na área jurídica.

A esse respeito, cumpre mencionar que, já em 2000, era grande o percentual de graduados em Direito que não exerciam profissões jurídicas.

Com efeito, na Tabela 5 do estudo realizado por Edson Nunes e Márcia Carvalho (2005), consta que, naquele ano, apenas $51,3 \%$ dos bacharéis em Direito exerciam profissões na área jurídica, enquanto que $48,7 \%$ atuavam em outras áreas.

Já no ano de 2010, como se verifica nos estudos realizados pela Fundação Getúlio Vargas (2014), 80\% dos formados em Direito estavam trabalhando, sendo que, desse total, apenas $42,4 \%$ trabalhava como advogado ou jurista, enquanto que os outros $57,6 \%$ atuavam em outras áreas, muito embora, nesses dez anos a quantidade de cursos jurídicos tenha saltado de 442 para 1.092, o número de matrículas em cursos de Direito tenha subido de 370 mil para 694 mil e o de graduações em Direito de 41.900 para 91 mil.

Portanto, considerando que o crescimento do número de bacharéis em Direito foi acompanhado de uma redução significativa do percentual de graduados que atuam na área jurídica, verifica-se que uma significativa maioria dos bacharéis formados nesse bacharelismo do século XXI não tem sido preparada adequadamente pelas faculdades de Direito do Brasil para atuar na área jurídica.

Outro levantamento importante para corroborar essa conclusão diz respeito ao desempenho das faculdades de Direito nas avaliações realizadas pelo Ministério da Educação (MEC). Embora sejam vários os instrumentos e indicadores complementares de avaliação dos cursos de nível superior, optouse, em razão da maior abrangência dos critérios de avaliação, pela utilização dos resultados do Conceito Preliminar de Curso (CPC), que é composto:

[...] pela nota do ENADE, pelo Indicador de Diferença entre os Desempenhos Observado e Esperado (IDD) e por fatores que consideram as titulações dos professores, o percentual de docentes 
que cumprem regime parcial ou integral (não horistas), recursos didáticos-pedagógicos, infraestrutura e instalações físicas (FUNDAÇÃO GETÚLIO VARGAS, 2014, p. 53)

Ocorre que, como também aponta o estudo realizado pela FGV, "apenas 26,5\% dos cursos de graduação em Direito obtiveram desempenho satisfatório (CPCs Faixa 4 ou 5)" (FUNDAÇÃO GETÚLIO VARGAS, 2014, p. 54), sendo a média geral correspondente à pontuação de 2,62, situada na Faixa 3, que é a mínima necessária para que o curso continue funcionando regularmente.

Não há, portanto, como dissociar a inaptidão de muitos bacharéis em Direito formados no contexto do novo bacharelismo das deficiências inerentes ao ensino jurídico prestado pelas instituições de ensino superior, que, em sua maioria, são da rede privada.

Além disso, é interessante apresentar outro dado relativo ao perfil dos bacharéis em Direito da atualidade, que diz respeito à renda média dos mesmos.

Conforme a Tabela 15 do estudo elaborado pela FGV (2014), a renda média dos profissionais formados em Direito, em 2010, era de $R \$ 5.164,00$ (cinco mil, cento e sessenta e quatro reais), o que, segundo dados de uma outra pesquisa da FGV (2015), situava a maioria dos profissionais do Direito na Classe econômica "C".

A partir desses dados, pode-se concluir que ao contrário do que esperam muitos dos calouros que ingressam nos milhares de cursos jurídicos espalhados pelo Brasil, a graduação em Direito, em regra, não tem sido suficiente para permitir que eles passem a fazer parte da elite econômica do país.

Por último, é importante fazer a ressalva de que as deficiências acima apontadas, relativas à maioria das faculdades de direito do país, não excluem o fato de que os cargos da elite jurídica e política nacional continuam sendo ocupados por bacharéis em Direito oriundos, principalmente, de determinadas instituições de ensino superior consideradas "de elite" (ALMEIDA, 2010).

Com efeito, em sua tese de doutorado, Almeida chegou a importantes conclusões a esse respeito, como se vê nos fragmentos abaixo transcritos:

Assim, os dados apresentados ao longo desta tese permitem afirmar a importância de certos capitais simbólicos e da combinação deles, 
para o posicionamento de agentes do campo jurídico no círculo de suas elites. Mais especificamente, parece-me que membros de diferentes grupos de elites da administração da justiça compartilham certos capitais simbólicos comuns, o que explica seu interreconhecimento e a legitimidade, perante seus pares, de suas posições de poder.

O mais evidente desses capitais parece ser o capital simbólico originário do título de formação superior, do diploma de uma faculdade de direito de elite. A análise de currículos e biografias de membros de diferentes grupos e hierarquias das elites jurídicas, feita no Capítulo 3, permitiu identificar um campo de instituições de ensino superior de elite - as fundadas no Império, as primeiras escolas livres da República e as confessionais católicas, seguidas de poucos cursos privados laicos surgidos antes da massificação do ensino jurídico da década de 1990 -, cujo diploma confere a seus egressos um acesso privilegiado ao campo político da justiça. Isso não quer dizer que todos os seus egressos estejam destinados à liderança da administração da justiça estatal e que não venham, por ventura, a ocuparem posições inferiores no campo, lado a lado com egressos de faculdades de menor prestígio. [...]

De qualquer forma, parece-me que, entre todos os capitais simbólicos identificados e analisados nesta tese, o capital conferido pelo diploma de uma faculdade de direito de elite é aquele mais amplamente compartilhado pelas elites jurídicas - sejam elas lideranças institucionais ou corporativas, especialistas ou ministros da Justiça, estejam elas posicionadas nas instâncias de alcance nacional ou em posições dominantes apenas de sistemas de justiça locais. (ALMEIDA, 2010, p. 290-291)

$\mathrm{Na}$ verdade, diz-se que os cursos de Direito perderam o seu caráter elitista levando-se em consideração os dados relativos à maior parte das faculdades e dos bacharéis em Direito do Brasil, o que não implica em dizer que o diploma de graduação em Direito tenha deixado de ser significativo para a ocupação dos cargos políticos e jurídicos do país.

\section{Considerações finais}

Ao longo do presente artigo, foi possível observar que alguns elementos culturais, políticos e sociais do período colonial marcaram profundamente 0 modo como o ensino jurídico e as profissões jurídicas surgiram e se desenvolveram no Brasil, havendo estreita relação entre a pedagogia livresca, retórica e conservadora dos jesuítas e a cultura bacharelesca surgida no período imperial, em que havia uma distância muito grande entre o discurso liberal dos bacharéis e suas práticas conservadoras e a preocupação excessiva com uma aparência de erudição, baseada em discursos ornamentados por 
palavras rebuscadas, por expressões em língua estrangeira, dentre outros elementos.

Do mesmo modo, pôde-se perceber que o personalismo e o patrimonialismo presentes no cenário colonial e a aversão dos portugueses ao trabalho disciplinado e racionalizado ajudam a explicar a proliferação de bacharéis em Direito, ocorrida no período imperial, bem como o fato de a má qualidade do ensino jurídico prestado pelas primeiras faculdades de Direito e da postura dos bacharéis de valorizar mais a forma que o conteúdo de seus discursos não ter sido um empecilho para que os mesmos ocupassem os espaços de poder naquele momento histórico.

Viu-se, também, que essa proliferação de bacharéis ocorrida no século XIX, com o intuito de formar o quadro de pessoal responsável pelo gerenciamento do Império, fez com que importantes expoentes da historiografia crítica brasileira, a exemplo de Sérgio Buarque de Holanda e Sérgio Adorno, passassem a utilizar o termo "bacharelismo", para designar tal fenômeno, cujo significado também passou a ser atrelado à prática profissional dos bacharéis em Direito.

Em outro momento, observou-se que esse bacharelismo surgido no período imperial entrou em crise com o advento do período republicano, tanto pelo maior protagonismo dos militares no cenário político nacional quanto pela incapacidade técnica de muitos bacharéis de lidar com a crescente complexidade do ordenamento jurídico pátrio, que passou a depender de conhecimentos técnicos buscados em outras áreas do conhecimento.

Então, já no último tópico do presente trabalho, verificou-se que no final do século $X X$ e no início do século XXI houve um crescimento exponencial do número de cursos de Direito e de estudantes e bacharéis, que tornou possível se falar em um retorno do bacharelismo. Entretanto, em razão das grandes diferenças que apresenta em relação ao do período imperial, denominou-se tal fenômeno de "novo bacharelismo" ou de "bacharelismo do século XXI".

Com efeito, embora o bacharelismo tradicional coincida, em alguns pontos, com o que se denominou de "bacharelismo do século XXI", como, por exemplo, no fato de ambos terem resultado de uma grande proliferação de bacharéis em Direito nos momentos históricos em que surgiram, e de, em 
ambos os casos, o ensino jurídico prestado pelas faculdades de Direito serem de má qualidade, as distinções entre eles são patentes.

Enquanto, no tradicional, o ensino jurídico era prestado apenas por instituições públicas de ensino superior, no novo bacharelismo, as instituições privadas são responsáveis por quase $90 \%$ dos cursos de Direito em que os bacharéis obtêm seus diplomas.

Por outro lado, enquanto o bacharelismo tradicional era profundamente elitista, na medida em que a má qualidade do ensino jurídico não impedia o acesso dos bacharéis à elite política responsável pelo gerenciamento do Estado imperial ${ }^{9}$ e que primava, inclusive, pela "aparência elitista" dos bacharéis, que deveriam transmitir a impressão de que eram pessoas cultas, com conhecimento não só do Direito, mas também de literatura e de outros elementos considerados sofisticados, o que se verifica no bacharelismo do século XXI é uma espécie de deselitização da graduação em Direito.

Diz-se isto porque, como se viu no tópico anterior, além de os números apresentados revelarem que há uma verdadeira massificação do ensino jurídico na conjuntura atual, o fato de, atualmente, serem exigidos conhecimentos técnicos para o exercício das profissões jurídicas, inclusive para a advocacia, faz com que a ascensão social buscada através do diploma de graduação em Direito tenha se tornado muito mais difícil. Fato este que é corroborado pelos dados que mostram que menos de $20 \%$ dos bacharéis conseguem atingir a pontuação mínima para se tornarem advogados e que, atualmente, a maioria dos bacharéis em Direito não atua em profissões jurídicas.

Ademais, outro reflexo decorrente do caráter técnico e impessoal que passaram a ter as seleções dos candidatos aptos a exercerem as profissões jurídicas foi a desvalorização da aparência de erudição do bacharel, que se tinha no período imperial.

$\mathrm{Na}$ verdade, como o interesse das instituições privadas de ensino é obter o máximo de estudantes matriculados em suas faculdades de Direito e o

\footnotetext{
${ }^{9}$ Isto porque tal acesso, naquele momento histórico, dependia das relações pessoais e políticas que o bacharel tinha com os detentores do poder, ao invés de ser uma seleção baseada em critérios técnicos e impessoais.
} 
alcance dessa meta está diretamente relacionado à quantidade de estudantes aprovados em concursos públicos ou em exames da $\mathrm{OAB}$, o ensino, em regra, passou a ser profundamente tecnicista ${ }^{10}$, deixando de haver 0 fomento a atividades literárias, jornalísticas e culturais que se tinha nas faculdades de Direito do século XIX e até mesmo a preocupação com a capacidade argumentativa e retórica dos discentes.

Assim, observa-se que, além dos problemas históricos surgidos desde a época da criação das primeiras faculdades de Direito do país, o ensino jurídico brasileiro, no contexto do bacharelismo do século XXI, tem tido que lidar com novos desafios oriundos desse novo fenômeno, marcado por uma proliferação de cursos jurídicos que não têm preparado adequadamente os bacharéis para exercerem as profissões jurídicas.

As causas dessa deficiência desbordam do objeto deste artigo. Entretanto, para encerrar o presente trabalho, é importante tecer algumas breves considerações a respeito das consequências desse novo bacharelismo sobre as instituições do sistema de justiça deste país, de modo a ressaltar a relevância do tema discutido para a conjuntura nacional hodierna.

Em primeiro lugar, é importante observar que, como afirma Ramos (2010) no cenário jurídico e político atual, o Poder Judiciário tem estado cada vez mais presente na sociedade brasileira, intervindo em assuntos que antes eram restritos à atuação dos demais poderes, eleitos democraticamente pelo voto popular.

Assim, ante a falta de eleição dos membros que compõem o terceiro poder, é da fundamentação racional de suas decisões que advém a legitimidade dos atos do poder Judiciário (ALEXY, 2011), sendo este o motivo que faz com que Eduardo Appio (2010) afirme que tal exigência é um imperativo da democracia brasileira.

\footnotetext{
10 "Quem percorre os programas de ensino de nossas escolas, e, sobretudo, quem houve as aulas que nelas se profere, sob a forma elegante e indiferente da velha aula-douta Coimbrã, vê que o objetivo atual do ensino jurídico é proporcionar aos estudantes, o conhecimento descritivo e sistemático das instituições e normas jurídicas." (RODRIGUES, 1995, p. 11)
} 
Entretanto, se a formação dos juristas é deficiente, evidentemente que restará comprometida a capacidade dos magistrados de fundamentar racionalmente suas decisões e a capacidade dos demais atores que atuam no processo judicial de se insurgir contra eventuais arbitrariedades ou subjetivismos advindos do órgão judicante.

Em segundo lugar, também é útil ressaltar que, como afirma Silveira (2007), ao se voltar apenas para o aprendizado acerca das leis vigentes, deixando de incentivar os juristas a refletir criticamente sobre o Ordenamento Jurídico e sobre a repercussão das normas jurídicas na sociedade em que vivem e atuam, o ensino jurídico deixa de contribuir para a mudança da cultura jurídica do país, necessária para a superação de problemas históricos como o da morosidade do Poder Judiciário.

Por fim, também merece destaque a irreverente crítica feita por Roberto Lyra Filho (1980) à alienação advinda desse ensino jurídico demasiadamente legalista e tecnicista, que se tornou hegemônico nesse contexto do bacharelismo do século XXI e que reduz o Direito às normas estatais, fazendo com que, de um lado, considere-se aceitável qualquer conteúdo inscrito na norma advinda do Estado e, por outro lado, que se negue normatividade a qualquer direito que não venha diretamente do Estado, a exemplo daqueles oriundos de tratados internacionais ${ }^{11}$.

Vê-se, portanto, que não são apenas os interesses dos estudantes de Direito que são comprometidos com a deficiência do ensino jurídico que vem sendo prestado pelas faculdades de Direito. Embora as consequências acima apontadas não sejam as únicas, elas são suficientes para demonstrar que a reflexão a respeito do ensino que vem sendo dado aos milhares de bacharéis em Direito que, semestralmente, obtêm seus diplomas é algo que reflete no

\footnotetext{
11 "Se dizemos, a propósito do Direito, que este é as normas estatais, além de contrair-se, arbitrariamente, a dialética do jurídico, fica em aberto o que tais normas pretendem veicular. Isto é, o passageiro é definido pelo automóvel e tudo que nele transita é passageiro. Se o motorista põe ali um saco de batatas, este saco passa a ser batata jurídica pelo simples fato do depósito. [...] A outra face do mesmo erro leva o positivista a negar "positividade" ao que não é Direito estatal [...]. Se existem, como vimos, Direitos não estatais, [...] afirma-se que na verdade tais Direitos não são um Direito direitinho, pois que o são impropriamente, insuficientemente, ou de todo não o são. [...] Com isso, desaparece todo e qualquer Direito que não seja de fonte estatal, como o direito de resistência às suas determinações antijurídicas, até os Direitos que se estabelecem acima dos Estados, como o Direito internacional." (LYRA FILHO, 1980, p. 21)
} 
modo de agir do Poder Judiciário e, consequentemente, na sociedade brasileira como um todo.

\section{Referências}

ADORNO, Sérgio. Os aprendizes do poder: o bacharelismo liberal na política brasileira. Rio de Janeiro: Paz e Terra, 1988.

ALEXY, Robert. Teoria da Argumentação Jurídica. Tradução Zilda

Hutchinson Schikd Silva, 3. ed. Rio de Janeiro: Forense, 2011.

ALMEIDA, Frederico Normanha Ribeiro de. A nobreza togada: as elites jurídicas e a política da justiça no Brasil. São Paulo. Tese (Doutorado em Ciência Política). Universidade de São Paulo, 2010. Disponível em:

$<$ http://www.teses.usp.br/teses/disponiveis/8/8131/tde-08102010-143600/ptbr.php>

APPIO, Eduardo. O controle judicial de políticas públicas no Brasil. 4 ed. reimp. Curitiba: Juruá, 2010

BOURDIEU, Pierre. O poder simbólico. Tradução de Fernando Tomaz. Rio de Janeiro: Bertrand Brasil, 2004.

CHAUÍ, Marilena. Cultura e Democracia: o discurso competente e outras falas. São Paulo: Cortez, 2006.

FONSECA, Ricardo Marcelo. Vias da modernização jurídica brasileira: a cultura jurídica e os perfis dos juristas brasileiros do século XIX. In: Revista Brasileira de Estudos Políticos. v. 98, p.257-294, 2008. Disponível em: $<$ www.pos.direito.ufmg.br/rbep/index.php/rbep/article/view/76>

FREYRE, Gilberto. Casa Grande \& Senzala: formação da família brasileira sob o regime da economia patriarcal. 29. ed. Rio de Janeiro: Record,1994.

FUNDAÇÃO GETÚLIO VARGAS. Exame de Ordem em Números. Vol. II. Rio de Janeiro: FGV Projetos. 2014.

Qual a faixa de renda familiar das classes? Vol. II.

Rio de Janeiro: FGV Projetos. 2014. Disponível em: <

http://cps.fgv.br/node/3999>. Acesso em 14. jul. 2015.

HOLANDA, Sergio Buarque de. Raízes do Brasil. 26. ed. Rio de Janeiro:

Companhia das Letras, 1995. 
INSTITUTO BRASILEIRO DE GEOGRAFIA E ESTATÍSTICA. Metodologia das estimativas da população residente nos municípios brasileiros com data de referência em $1^{\circ}$ de julho de 2012. Disponível em: < ftp://ftp.ibge.gov.br/Estimativas de Populacao/Estimativas 2012/metodologia 2012.pdf $>$. Acesso em. 14. jul. 2015.

KOZIMA, José Wanderley. Instituições, retórica e o bacharelismo no Brasil. In: WOLKMER, Antônio Carlos (Org.). Fundamentos de História do Direito. 8.ed. rev. e atual. Belo Horizonte: Del Rey, 2014. p. 477-499.

LYRA FILHO, Roberto. $O$ direito que se ensina errado. Brasília: Centro Acadêmico de Direito da Universidade de Brasília, 1980.

NUNES, Edson; CARVALHO, Márcia. O Ensino e a Profissão Jurídica no Brasil: uma visão quantitativa. Documento de Trabalho n 43. 2005.

Observatório Universitário. Disponível em:

$<$ http://www.observatoriouniversitario.org.br/documentos de trabalho/documen tos de trabalho 43.pdf>. Acesso em 10. jul.2015.

ORDEM DOS ADVOGADOS DO BRASIL. Brasil, sozinho, tem mais faculdades de Direito que todos os países. Disponível em: < http://www.oab.org.br/noticia/20734/brasilsozinho-tem-mais-faculdades-dedireito-que-todos-os-paises >. Acesso em. 13. jul. 2015.

. Provimento no144/2011 do Conselho Federal da OAB.

Disponível em: < http://www.oab.org.br/leisnormas/legislacao/provimentos/1442011>. Acesso em. 14. jul. 2015.

RAMOS, Elival da Silva. Ativismo judicial: parâmetros dogmáticos. São Paulo: Saraiva, 2010.

RODRIGUES, Horácio Wanderlei. Novo currículo mínimo dos cursos jurídicos. São Paulo: RT, 1995.

SILVEIRA, Fabiana Rodrigues. A morosidade no Poder Judiciário e seus reflexos econômicos. Porto Alegre: Sergio Antonio Fabris, 2007 VENÂNCIO FILHO, Alberto. Das Arcadas do Bacharelismo: 150 anos de ensino jurídico no Brasil. 2. ed. 1. reimp. São Paulo: Perspectiva, 2004. WOLKMER, Antônio Carlos. História do Direito no Brasil. 5. ed. Rio de Janeiro: Forense, 2010. 